\title{
Phân tích tổng họ̣p ba nhóm họ gen EBNAS LMPS và EBERS của Epstein-Barr Virus - Một trong những nguyên nhân chính dẫn đến bệnh ung thư vòm họng
}

\section{Meta-analysis: Epstein-Barr Virus genes - EBNAS, LMPS, and $E B E R S$ one of the major causes of nasopharyngeal cancer}

\author{
Nguyễn Hoàng Anh Tuấn ${ }^{1}$, Thiều Hồng Huệ, Lao Đức Thuận ${ }^{2 *}$, Lê Huyền Ái Thúy ${ }^{2}$ \\ ${ }^{1}$ Trường Đại học Khoa học Tự Nhiên, Thành phố Hồ Chí Minh, Việt Nam \\ ${ }^{2}$ Trường Đại học Mở Thành phố Hồ Chí Minh, Việt Nam
}

*Tác giả liên hệ, Email: thuan.ld@ou.edu.vn

THÔNG TIN

DOI: $10.46223 / \mathrm{HCMCOUJS}$.

tech.vi.14.1.437.2019

Ngày nhận: 15/08/2019

Ngày nhận lại: 17/09/2019

Duyệt đăng: 17/09/2019

Tù khóa:

Epstein-Barr virus, phân tích tổng hợp, ung thư vòm họng, Việt Nam

\section{TÓM TẮT}

Ung thư vòm họng (UTVH) là loại ung thư rất phổ biến tại Việt Nam. Sự xâm nhiễm Epstein-Barr Virus (EBV) đã được chứng minh là một nguyên nhân chính dẫn đến sự hình thành khối $\mathrm{u}$ vòm họng. Tuy nhiên, tại Việt Nam, các công trình nghiên cứu, đặc biệt liên quan đến tính chất phân tử của $\mathrm{EBV}$ vẫn còn rất nhiều hạn chế. Trong nghiên cứu này, cơ sở dữ liệu khoa học được khai thác, xây dựng nhằm xây dựng cơ sở khoa học về tính chất phân tử của $\mathrm{EBV}$ làm nền tảng cho các nghiên cứu sau này. Nghiên cứu này được thực hiện nhằm tập trung vào phân tích 3 nhóm gen chính của $\mathrm{EBV}$ bằng phương pháp phân tích tổng hợp. Kết quả cho thấy các nghiên cứu trên thế giới chủ yếu tập trung ở các gen $E B N A-1, L M P-1$ và $E B E R$. Kết quả phân tích cho thấy, tỷ lệ phát hiện các gen $E B N A-1 L M P-1$ và $E B E R$ lần lượt là $92.12 \% ; 78.93 \%$ và $88.12 \%$. Ngoài ra, mô hình phân tích ngẫu nhiên được áp dụng để phân tích chỉ số nguy cơ (RR) và tỷ suất chênh $(\mathrm{OR})$ với kết quả lần lượt là: $E B N A-1 \quad \mathrm{RR}=20.10 ; \mathrm{OR}=332.75 ; L M P-1$ $\mathrm{RR}=3.63 ; \mathrm{OR}=17.9$ và $E B E R \mathrm{RR}=5.4 ; \mathrm{OR}=46.11$. Kết quả phân tích cũng khẳng định rằng: sự hiện diện các gen của $\mathrm{EBV}$ có mối liên quan mạnh đến sự hình thành khối $\mathrm{u}$ vòm họng. Đồng thời, kết quả phân tích cũng chỉ ra rằng: về mặt phương pháp: PCR là phương pháp được sử dụng chủ yếu trong các nghiên cứu; về loại mẫu sử dụng: loại mẫu mô sinh thiết là loại mẫu được sử dụng nhiều nhất trong các nghiên cứu về ung thư. Tóm lại, chúng tôi xây dựng thành công cơ sở phân tử về sự hiện diện các gen của EBV liên quan đến tần số hiện diện, các giá trị $\mathrm{OR}, \mathrm{RR}$. Từ đó, các dữ liệu này làm nền tảng cho các nghiên cứu thực nghiệm trên chính mẫu UVTH thu nhận từ người Việt Nam. 
Keywords:

Epstein-Barr virus, metaanalysis, nasopharyngeal carcinoma, Vietnam

\section{ABSTRACT}

Nasopharyngeal cancer is the most common cancer of head and neck cancer in Vietnam. The infection of Epstein-Barr Virus (EBV) has been reported to be the cause of nasopharyngeal tumorigenesis. In Vietnam, the studies relevant to EBV, especially the molecular of EBV, are still limited. In the current study, the databases were systematically analyzed to establish the scientific basis for the molecular of EBV which could be applied in further studies. This study was focused on the analysis of three families of EBV genes, included EBNAs, LMPs and EBER based on a meta-analysis. As the result, most studies were focused on the detection of EBNA-1,LMP-1 and EBER. The frequencies of EBNA-1, LMP-1 and EBER were $92.12 \%$; 78.93\% and $88.12 \%$, respectively. Moreover, a random effect model was applied to calculate the $\mathrm{OR}$ and RR: $E B N A-1: \mathrm{RR}=20.10 ; \mathrm{OR}=332.75$; $L M P-1: \mathrm{RR}=3.63 ; \mathrm{OR}=17.9$ and $E B E R: \mathrm{RR}=5.4 ; \mathrm{OR}=46.11$. Those results indicated that the presence of EBV genes was significantly associated with nasopharyngeal carcinoma. According to the method, PCR was the common method used for the detection of the EBV genes' presence. Moreover, the nasopharyngeal biopsy was the main source of samples enrolled in nasopharyngeal cancer studied. In summary, we successfully conducted the molecular database about the presence of EBV genes, included the frequency, $O R$ and $R R$ value to be the scientific database for further studies relevant to nasopharyngeal cancer in the Vietnamese population.

\section{Giới thiệu}

Ung thư vòm họng (UTVH) là loại ung thư phổ biến nhất trên thế giới ở vùng đầu và cổ (Chan, Bray, \& McCarron, 2005). Theo nghiên cứu của Salehiniya, Mohammadian, Mohammadian-Hafshejani, và Mahdavifar (2018), bệnh UTVH có sự phân hóa về địa lý rất rõ rệt với $81 \%$ ca phân bố ở khu vực châu Á, $9 \%$ tập trung ở châu Phi và $10 \%$ còn lại phân bố rải rác khắp nơi trên thế giới. Ngoài ra, tỷ lệ mắc bệnh UTVH của nam giới cao gấp 2-3 lần so với nữ giới. Việt Nam tuy là nước có tỷ lệ mắc bệnh UTVH thấp nhất nhưng tỷ lệ tử vong của người bệnh UTVH lại rất cao, Việt Nam xếp thứ 6 trên toàn thế giới về tỷ lệ mắc bệnh UTVH với chỉ số ASR là 5.7 và tỷ lệ tử vong là 3.9 (Global cancer observatory: http://gco.iarc.fr/).

Ba nguyên nhân chính dẫn đến sự hình thành của bệnh UTVH: (1) Yếu tố môi trường: Như đã được đề cập ở trên, bệnh UTVH có tính đặc trưng theo khu vực địa lí và đặc biệt khu vực châu Á là nơi có tỷ lệ mắc bệnh UTVH cao nhất. Đáng chú ý hơn các nghiên cứu gần đây đưa ra bằng chứng rõ rệt về thói quen ăn uống của người dân trong khu vực châu Á là một trong những nguyên nhân hàng đầu làm tăng nguy cơ mắc bệnh UTVH. (2) Yếu tố di truyền: Những 
nghiên cứu của Chen và Huang (1997); Chang và Adami (2006); Ekburanawat và cộng sự (2010) đã chỉ ra rằng những người trong một gia đình có người từng mắc bệnh UTVH sẽ có nguy cơ mắc bệnh UTVH cao hơn gấp 4-10 lần. (3) Epstein-Barr Virus (EBV): Vào năm 1966, nghiên cứu của Old, Boyse, và Oettgen trên những mẫu huyết thanh của người bệnh có sự hiện hiện $\mathrm{EBV}$ từ đó đưa ra giả thuyết đầu tiên về mối liên hệ giữa EBV và bệnh UTVH. Các nghiên cứu của Stevens và cộng sự (2006); Cho (2007) và Frappier (2013) cho thấy phát hiện sự hiện diện của EBV là một trong những dấu chứng sinh học (biomarker) tìm năng để hỗ trợ tiên lượng và chẩn đoán sớm bệnh UTVH.

Epstein-Barr Virus (EBV), hay còn gọi là human herpesvirus 4, được phát hiện lần đầu vào năm 1964 bởi Epstein và cộng sự. EBV thuộc họ Herpesviridae, phân họ Gammaherpesvirinae, chi Lymphocryptovirus, loài Human Herpes virus 4 (HHV4) (Wang, Rivailler, Rao, \& Cho, 2001). Bộ gen của EBV có cấu trúc là DNA sợi đôi dài khoảng 184kps mã hóa cho hơn 85 gen trong đó có ba họ gen đóng vai trò quan trọng: EBNAs (EBV nuclear antigens), LMPs (Latent membrane proteins) và EBERs (Non-coding nuclear RNAs) (Kieff \& Rickinson, 2001). Chức năng chính của các gen trong 3 họ gen được đề cập: $E B N A-1$ có chức năng sao chép bộ genome của $E B V$, phân chia episome của virus trong nguyên phân, góp phần tạo nên sự bất tử của tế bào; $E B N A-2$ đóng vai trò là yếu tố kích hoạt đồng phiên mã giúp biểu hiện vượt mức các gen của virus và tế bào, góp phần tạo nên sự bất tử của tế bào; $L M P-1$ giả dạng tín hiệu của CD40 ligand, tăng mức độ biểu hiện của $b c l-2$ và $a 20$, góp phần tạo nên sự bất của tử tế bào; $L M P-2$ đưa $\mathrm{EBV}$ vào trạng thái tiềm tàn, đóng vai trò là một gen oncogen trong hội chứng Hodgkin và UTVH [8]. EBERs bao gồm EBER1 và EBER2, là một trong những loại RNA không mã hóa xuất hiện trong giai đoạn tiềm tan của EBV (Kieff \& Rickinson, 2001).

Tại Việt Nam, các công trình nghiên cứu, đặc biệt liên quan đến tính chất phân tử của EBV vẫn còn rất nhiều hạn chế. Do đó, mục tiêu của bài báo này nhằm hướng tới xây dựng cơ sở dữ liệu khoa học về tính chất phân tử của EBV thông qua việc phân tích tổng hợp dựa trên các công trình nghiên cứu trên thế giới.

\section{Vật liệu và phương pháp}

\subsection{Thu thập dũ liệu}

Tiến hành khai thác dữ liệu trên ngân hàng dữ liệu NCBI bằng cách sử dụng một số từ khóa như: Nasopharyngeal carcinoma, nasopharyngeal cancer, Epstein-Barr Virus, EBNA-1, EBNA-2, LMP-1, LMP-2, EBERs, PCR, gene expression, real-time PCR.

Tìm kiếm thu thập thông tin về ung thư, ung thư vòm họng, tình hình nghiên cứu UTVH trên thế giới và tại Việt Nam. Các dữ liệu sau khi được thu thập sẽ được tiến hành phân tích tổng hợp meta-analysis nhằm so sánh, kiểm tra, sàng lọc các yếu tố ảnh hưởng đến sự khác biệt giữa các kết quả như: loại mẫu, phương pháp sử dụng, dân tộc, ...

\subsection{Phân tích tổng hợp}

Các bài báo sau khi được thu thập sẽ được tiến hành phân tích tổng hợp thông qua phần mềm MedCal nhằm phân tích các chỉ số: tỷ lệ mắc bệnh (Propotion), chỉ số nguy cơ tương đối (Relative risk-RR) và tỷ suất chênh (Odd ratio-OR). 


\section{Kết quả và biện luận}

Kết quả tìm kiếm và phân tích chọn lọc bài báo

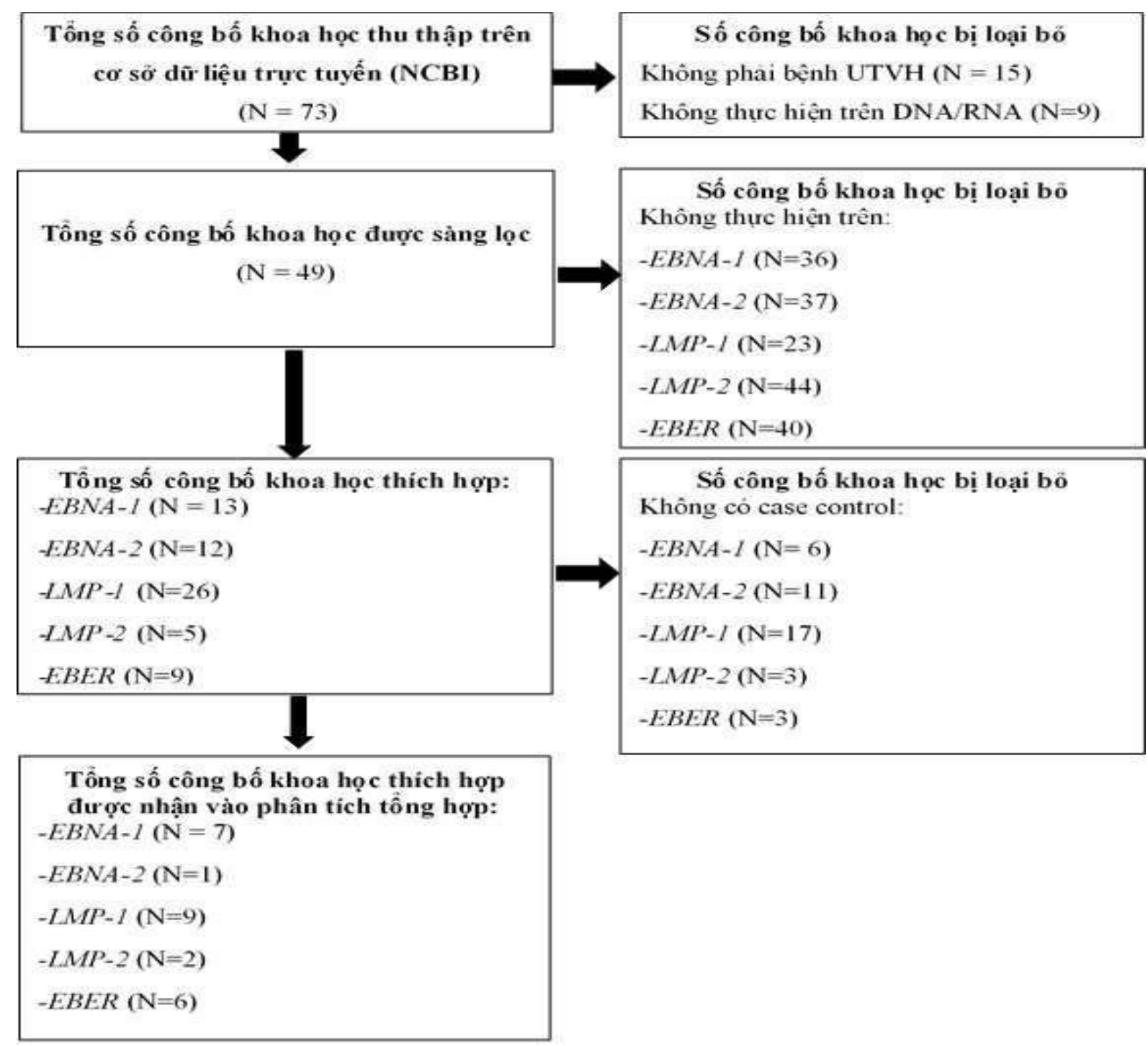

Hình 1.

Trong số tổng 19 bài được chọn lọc vào bộ dữ liệu nghiên cứu tổng hợp trong đó có nghiên cứu về các gen mục tiêu $E B N A-1, E B N A-2, L M P-1, L M P-2$ và $E B E R$ lần lượt là $7,1,9$, 2 và 6 bài (Hình 1$)$. Phương pháp được sử dụng chủ yếu trong các nghiên cứu này là $\mathrm{PCR}$ (11/19) còn lại là các phương pháp RT PCR (3/19), real time PCR (1/19) và ISH (4/19); đáng chú ý hơn đối với gen $E B E R$ phương pháp sử dụng chủ yếu là phương pháp ISH còn các phương pháp PCR hay RT-PCR rất ít. Các nghiên cứu được thực hiện chủ yếu trên những người bệnh ở các quốc gia thuộc châu Á như: Trung Quốc, Đài Loan, Mã Lai (14/19). Các nguồn mẫu được sử dụng trong các nghiên cứu cũng rất đa dạng: sinh thiết $(8 / 19)$, dịch phết $(3 / 19)$, mẫu máu (3/19) và mô đúc parafirm (6/19) (Bảng 1$)$. 
Hiện nay, các nghiên cứu chẩn đoán bệnh UTVH dựa trên phát hiện sự hiện diện của EBV chủ yếu được thực hiện trên các họ gen $E B N A, L M P$ và $E B E R$ tuy nhiên theo phân tích thống kê cho thấy: (1) đa số các nghiên cứu tập trung ở gen $E B N A-1, L M P-1$ và $E B E R$; (2) các nghiên cứu có thực hiện case control cũng rất ít trên các gen $E B N A-2$ và $L M P-2$ và cuối cùng (3) chưa có nghiên cứu nào thực hiện phát hiện sự hiện diện của EBV dựa trên đa gen (phát hiện sự hiện diện của ít nhất một gen trong 3 họ gen $E B N A, L M P$ và $E B E R$ ). Các loại mẫu được thực hiện trong các nghiên cứu rất đa dạng; hiện nay việc thực hiện các phương pháp chẩn đoán thông qua phương pháp không xâm lấn (sử dụng các loại mẫu dịch phết, các tế bào tự do lưu hành trong máu) dần trở nên phổ biến bởi độ nhạy và độ chính xác tương đương với loại mẫu xâm lấn (mô, sinh thiết) tuy nhên các nghiên cứu sử dụng loại mẫu không xâm lấn trên bệnh UTVH rất ít và đặc biệt tại Việt Nam hiện chưa có nghiên cứu nào thực hiện trên mẫu dịch phết. Bệnh UTVH có tính đặc trưng theo vị trí địa lý và dân tộc đặc biệt hơn là tập trung chủ yếu ở châu Á, tuy nhiên các nghiên cứu về bệnh UTVH ở Việt Nam nói chung và miền Nam Việt Nam chưa được quan tâm mà tỷ lệ mắc bệnh và tử vong của bệnh UTVH tại Việt Nam đang xếp thứ 6 trên toàn thế giới. Vậy nên, việc phát triển một phương pháp nhằm tiên lượng và chẩn đoán sớm bệnh UTVH trên cộng đồng người Việt Nam là việc cấp thiết. 


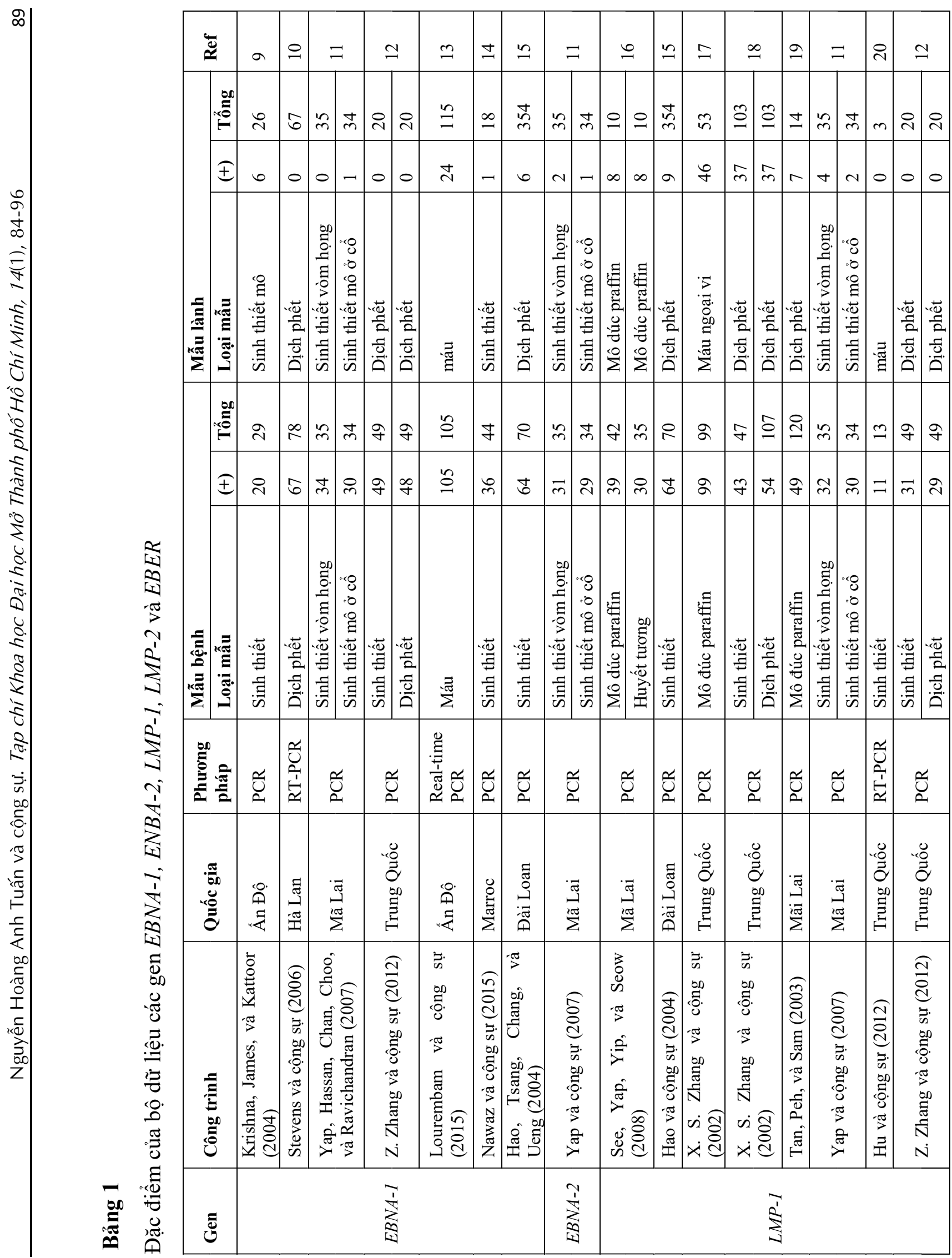




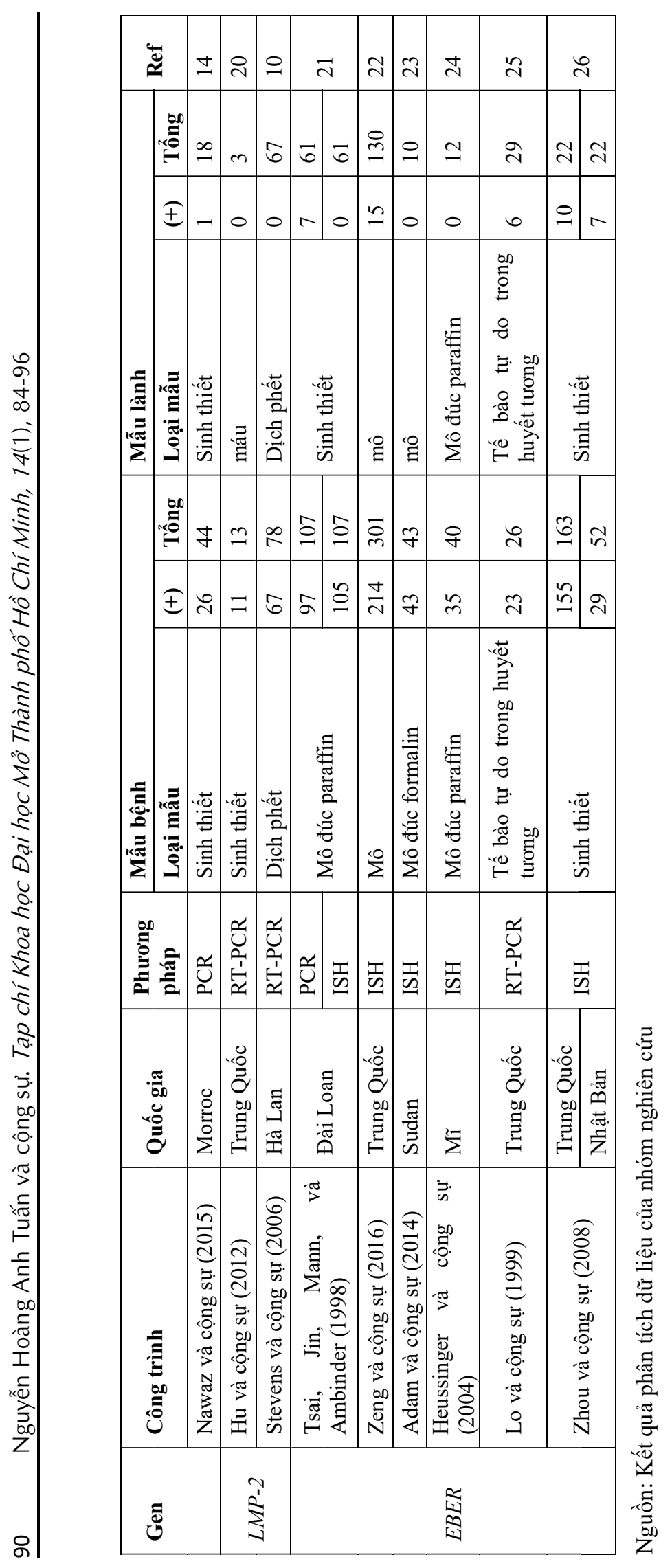


Phân tích tổng hợp các chỉ số tỷ lệ mắc bệnh, chỉ số nguy cơ và tỷ suất chênh

Các nghiên cứu khoa học sau khi được thống kê sẽ được tiến hành phân tích các chỉ số tỷ lệ phát hiện (Propotion), nguy cơ tương đối (Relative risk) và tỷ suất chênh (Odds ratio) bằng mô hình phân tích ảnh hưởng biến thiên (Random effect model) (Bảng 2).

Kết quả phân tích ghi nhận được:

- Đối với gen $E B N A-1$ : tần số phát hiện $\mathrm{EBV}$ trong các mẫu bệnh phẩm dao động từ $68.96 \%-100 \%$ và có trọng số trung bình là

$92.12 \%$ với $\mathrm{p}<0.0001$ và $95 \% \mathrm{CI}=74.72-91.89$; chỉ số nguy cơ tương đối dao động từ $2.98-116.2$ và có trọng số trung bình là 20.10 với $\mathrm{p}<0.0001$ và $95 \% \mathrm{CI}=77.23-92.49$; tỷ suất chênh dao động từ $7.40-4059$ và có trọng số trung bình là 332.75 với $\mathrm{p}<0.0001$ và $95 \% \mathrm{CI}=$ 62.05-89.12.

- Đối với gen $L M P-1$ : tần số phát hiện EBV trong các mẫu bệnh phẩm dao động từ $40.83 \%-100 \%$ và có trọng số trung bình là $78.93 \%$ với $\mathrm{p}<0.0001$ và $95 \% \mathrm{CI}=.85-96.41$; chỉ số nguy cơ tương đối dao động từ $0.81-35.96$ và có trọng số trung bình là 3.63 với $\mathrm{p}<0.0001$ và $95 \% \mathrm{CI}=95-74-97-65$; tỷ suất chênh dao động từ $0.69-120$ và có trọng số trung bình là 17.9 với $\mathrm{p}<0.0001$ và $95 \% \mathrm{CI}=86.12-93.91$;

- Đối với gen $E B E R$ : tần số phát hiện EBV trong các mẫu bệnh phẩm dao động từ $55.76 \%-100 \%$ và có trọng số trung bình là $88.12 \%$ với $\mathrm{p}<0.0001$ và $95 \% \mathrm{CI}=91.01-96.45$; chỉ số nguy cơ tương đối dao động từ $1.75-121.13$ và có trọng số trung bình là 5.4 với $\mathrm{p}<0.0001$ và $95 \% \mathrm{CI}=67.94-90.99$; tỷ suất chênh dao động từ 2.70-5190.6 và có trọng số trung bình là 46.11 với $\mathrm{p}<0.0001$ và $95 \% \mathrm{CI}=67.38-90.88$.

Dựa vào số liệu thống kê cho thấy tỷ lệ phát hiện EBV khi sử dụng gen $E B N A-1$ $(92.12 \%)$ là cao nhất và gen $L M P-1$ (78.93\%) sự khác biệt này được giải thích thông qua chức năng và hoạt động của từng loại gen cụ thể, $E B N A-1$ là gen luôn xuất hiện trong các quá trình hoạt động của EBV trong khi $L M P-1$ chỉ được kích hoạt trong quá trình biến đổi tế bào $\mathrm{B}$ và quá trình di cư xâm lấn của tế bào. Ngoài ra việc các nghiên cứu thực hiện trên các nguồn mẫu và phương pháp khác nhau cũng đem đến sự khác biệt về tần số phát hiện. Chỉ số nguy cơ tương đối và tỷ suất chênh cũng có sự khác biệt giữa các loại gen khác nhau. Do đó khảo sát sự có mặt của $\mathrm{EBV}$ bằng cách sử dụng đa gen sẽ giúp tăng độ nhạy và độ chính xác cho quá trình chuẩn đoán và tiên lượng bệnh. 


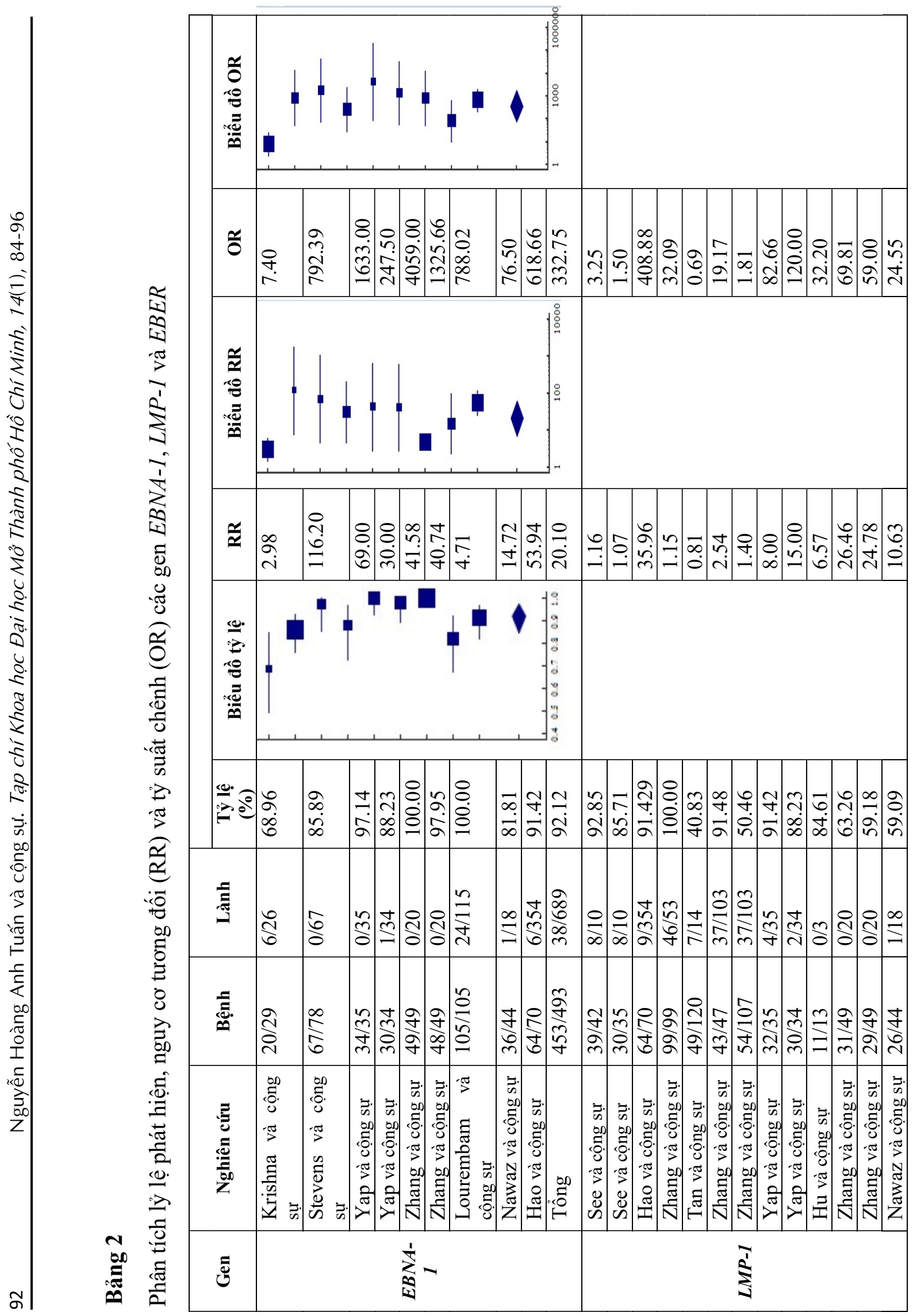




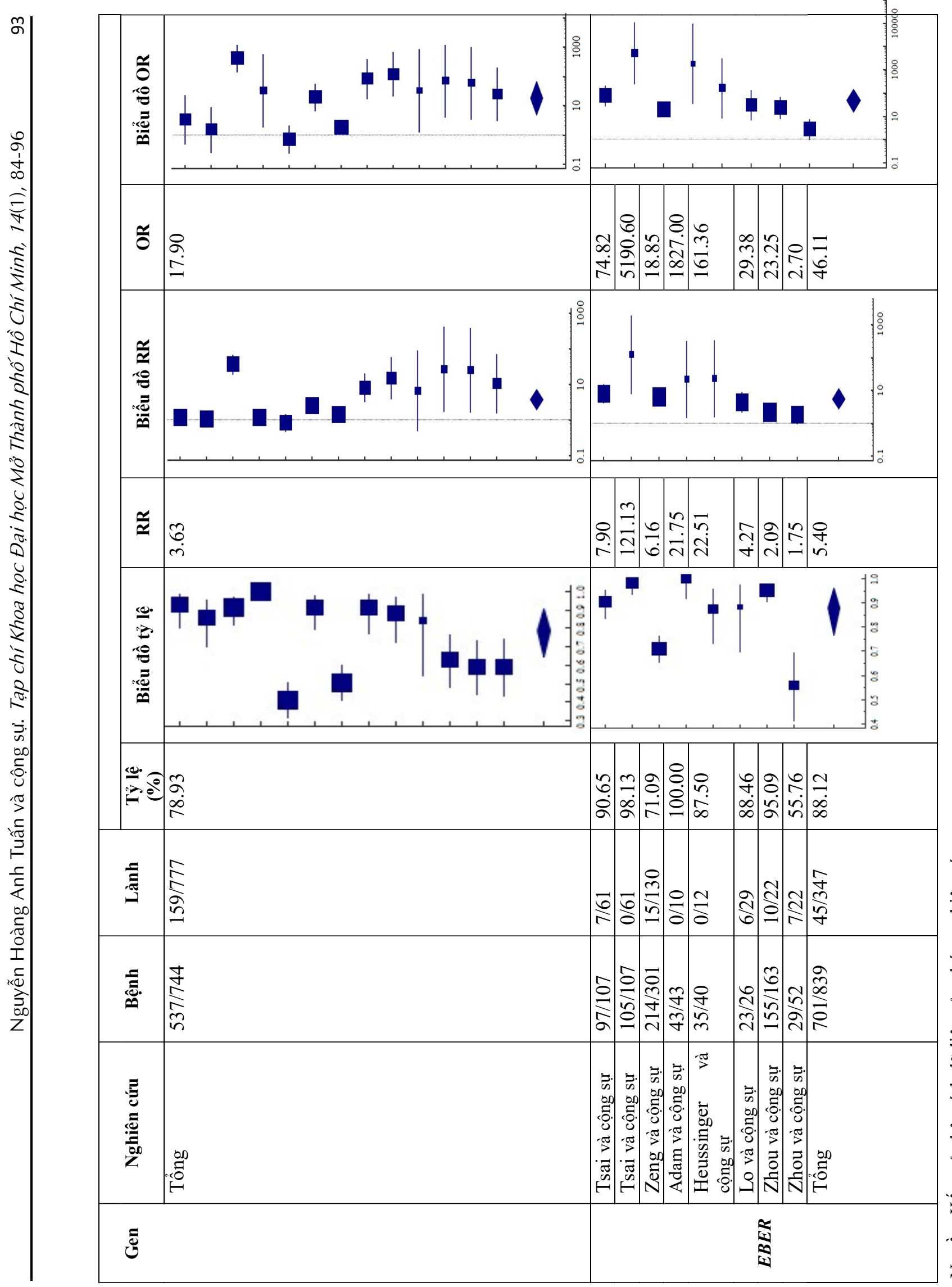

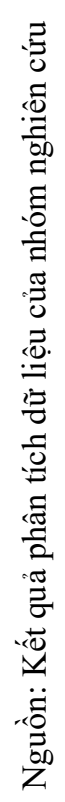




\section{Kết luận}

Kết quả phân tích thống kê chỉ ra rằng: (1) về mặt phương pháp: PCR là phương pháp được sử dụng chủ yếu trong các nghiên cứu trên thế giới; (2) về loại mẫu sử dụng: loại mẫu mô sinh thiết là loại mẫu được sử dụng nhiều nhất trong các nghiên cứu về ung thư; (3) về yếu tố nhiễm EBV: các nghiên cứu cho thấy có sự liên quan chặt chẽ giữa yếu tố nhiễm EBV và ung thư vòm họng thông qua 3 họ gen $E B N A s, L M P s$ và $E B E R s$ với tần số phát hiện lên đến $92.12 \%$ với $\mathrm{p}<0.0001 ; \mathrm{I}^{2}=85.86 \%$ và $95 \% \mathrm{CI}=74.72=91.90$; chỉ số nguy cơ $\mathrm{RR}=20.10$ với $\mathrm{p}<0.0001$; $\mathrm{I}^{2}=86.92 \%$ và $95 \% \mathrm{CI}=77.23-92.49$; tỷ suất chênh $\mathrm{OR}=332.75$ với $\mathrm{p}<0.0001 ; \mathrm{I}^{2}=79.68 \%$; $95 \% \mathrm{CI}=62.05-89.12$. Từ các thống kê trên có thể kết luận rằng, yếu tố nhiễm EBV là một trong những dấu chứng sinh học tiềm năng để tiên lượng và chẩn đoán sớm bệnh UTVH. Các dữ liệu này làm nền tảng cho các nghiên cứu thực nghiệm trên chính mẫu UVTH thu nhận từ người Việt Nam nhằm hướng tới xây dựng dấu chứng sinh học đặc trưng dựa trên yếu tố nhiễm ứng dụng trong chẩn đoán sớm UTVH ở người Việt Nam.

\section{Tài liệu tham khảo}

Adam, A. A. M., Abdullah, N. E., Hassan, L. A. M. E., Elamin, E., Ibrahim, M., \& Hassan, M. A. (2014). Detection of Epstein-Barr virus in nasopharyngeal carcinoma in Sudanse by in situ hybridization. Journal of Cancer Therapy, 5(6), 517-522.

Chan, J. K. C., Bray, F., \& McCarron, P. (2005). Nasopharyngeal carcinoma. In L. Barnes, J. W. Eveson, P. Reichart, \& D. L. Sidransky (Eds.), WHO calssification of tumours: Pathology and genetics of head and neck tumours (pp. 85-97). Lyon, France: IARC Press.

Chang, E. T., \& Adami, H. O. (2006). The enigmatic epidemiology of nasopharyngeal carcinoma. Cancer Epidemiology, Biomarkers \& Prevention, 15(10), 1765-1777.

Chen, D. L., \& Huang, T. B. (1997). A case-control study of risk factors of nasopharyngeal carcinoma. Cancer Letters, 117(1), 17-22.

Cho, W. C. (2007). Nasopharyngeal carcinoma: Molecular biomarker discovery and progress. Molecular Cancer, 6(1), 1-9.

Ekburanawat, W., Ekpanyaskul, C., Brennan, P., Kanka, C., Tepsuwan, K., Temiyastith, S., ... Sangrajrang, S. (2010). Evaluation of non-viral risk factors for nasopharyngeal carcinoma in Thailand: Results from a case-control study. Asian Pacific Journal of Cancer Prevention, 11(4), 929-932.

Frappier, L. (2013). EBNA-1 and Epstein-barr virus associated tumours. In Springer briefs in cancer research. New York, NY: Springer.

Hao, S. P., Tsang, N. M., Chang, K. P., \& Ueng, S. H. (2004). Molecular diagnosis of nasopharyngeal carcinoma: Detecting $L M P-1$ and EBNA by nasopharyngeal swab. Otolaryngol Head Neck Surg, 131, 651-654.

Heussinger, N., Büttner, M., Ott, G., Brachtel, E., Pilch, B. Z., Kremmer, E., \& Niedobitek, G. (2004). Expression of the Epstein-Barr virus (EBV) encoded latent membrane protein $2 \mathrm{~A}$ 
(LMP2A) in EB Vassociated nasopharyngeal carcinoma. The Journal of Pathology, 203(2), 696-699.

Hu, C., Wei, W., Chen, X., Woodman, C. B., Yao, Y., Nicholls, J. M., ... Arrand, J. R. (2012). A global view of the oncogenic landscape in nasopharyngeal carcinoma: An integrated analysis at the genetic and expression levels. Plos One, 7(7), Article e41055.

Kieff, E., \& Rickinson, A. B. (2001). Epstein-Barr virus and its replication. In B. N. Fields, D. M. Knipe, \& P. M. Howley (Eds.), Fields virology (4th ed.) (pp. 2511-2575). Philadelphia, PA: Lippincott-Raven.

Krishna, S. M., James, S., \& Kattoor, J. (2004). Serum EBV DNA as a biomarker in primary nasopharyngeal carcinoma of Indian origin. Japanese Journal of Clinical Oncology, 34(6), 307-311.

Lo, K. W., Lo, Y. M., Leung, S. F., Tsang, Y. S., Chan, L. Y., Johnson, P. J., ... Huang, D. P. (1999). Analysis of cell-free Epstein-Barr virus associated RNA in the plasma of patients with nasopharyngeal carcinoma. Clinical Chemistry, 45(8), 1292-1294.

Lourembam, D. S., Singh, A. R., Sharma, T. D., Singh, T. S., Singh, T. R., \& Singh, L. S. (2015). Evaluation of risk factors for nasopharyngeal carcinoma in a high-risk area of India, the North Eastern region. Asian Pacific Journal of Cancer Prevention: APJCP, 16(12), 4927-4935.

Min, Z., Young-sheng, Z., Jie-hua, H. E., Su-xia, L., Bi-ling, Z., \& Ying-jie, Y. (2004). Comparison of Epstein-Barr virus infection and $30 \mathrm{bp}$-deleted LMP1 gene among four histological types of nasopharyngeal carcinoma. Chinese Medical Journal, 117(4), 608611.

Nawaz, I., Moumad, K., Martorelli, D., Ennaji, M. M., Zhou, X., Zhang, Z., ... Hu, L.-H. (2015). Detection of nasopharyngeal carcinoma in Morocco (North Africa) using a multiplex methylation-specific PCR biomarker assay. Clinical Epigenetics, 7(1), Article 89.

Old, L. J., Boyse, E. A., \& Oettgen, H. P. (1966). Precipitating antibody in human serum to antigen present in cultured Burkitt lymphoma cell. Proceedings of the National Academy of Sciences of the United States of America, 56(6), 1699-1704. doi:10.1073/pnas.56.6.1699

Salehiniya, H., Mohammadian, M., Mohammadian-Hafshejani, A., \& Mahdavifar, N. (2018). Nasopharyngeal cancer in the world: Epidemiology, incidence, mortality and risk factors. World Cancer Research Journal, 5(1), e1046. doi:10.32113/wcrj_20183_1046

See, H. S., Yap, Y. Y., Yip, W. K., \& Seow, H. F. (2008). Epstein-Barr virus latent membrane protein-1 (LMP-1) 30-bp deletion and Xho I-loss is associated with type III nasopharyngeal carcinoma in Malaysia. World Journal of Surgical Oncology, 6(1), Article 18.

Stevens, S. J., Verkuijlen, S. A., Hariwiyanto, B., Harijadi, Paramita, D. K., Fachiroh, J., ... Middeldorp, J. M. (2006). Noninvasive diagnosis of nasopharyngeal carcinoma: Nasopharyngeal brushings reveal high Epstein-Barr virus DNA load and carcinomaspecific viral BARF1 mRNA. International Journal of Cancer, 119(3), 608-614. 
Tan, E. L., Peh, S. C., \& Sam, C. K. (2003). Analyses of Epstein-Barr virus latent membrane protein-1 in Malaysian nasopharyngeal carcinoma: High prevalence of 30-bp deletion, Xhol polymorphism and evidence of dual infections. Journal of Medical Virology, 69(2), 251-257.

Tsai, S. T., Jin, Y. T., Mann, R. B., \& Ambinder, R. F. (1998). Epstein-Barr virus detection in nasopharyngeal tissues of patients with suspected nasopharyngeal carcinoma. Cancer, 82(8), 1449-1453.

Wang, F., Rivailler, P., Rao, P., \& Cho, Y. G. (2001). Simian homologues of Epstein-Barr virus. Philosophical Transactions of the Royal Society of London. Series B: Biological Sciences, 356(1408), 489-497.

Yap, Y. Y., Hassan, S., Chan, M., Choo, P. K., \& Ravichandran, M. (2007). Epstein-Barr virus DNA detection in the diagnosis of nasopharyngeal carcinoma. Otolaryngol - Head and Neck Surgery, 136(6), 986-991. doi:10.1016/j.otohns.2006.11.027

Zeng, Z., Fan, S., Zhang, X., Li, S., Zhou, M., Xiong, W., ... Li, G. (2016). Epstein-Barr virusencoded small RNA 1 (EBER-1) could predict good prognosis in nasopharyngeal carcinoma. Clinical and Translational Oncology, 18(2), 206-211.

Zhang, X. S., Song, K. -H., Mai, H.-Q., Jia, W.-H., Feng, B.-J., Xia, J.-C., ... Zeng, Y.-X. (2002). The 30-bp deletion variant: A polymorphism of latent membrane protein 1 prevalent in endemic and non-endemic areas of nasopharyngeal carcinomas in China. Cancer Letters, 176(1), 65-73.

Zhang, Z., Sun, D., Hutajulu, S. H., Nawaz, I., Van, D. N., Huang, G., ... Hu, L. -H. (2012). Development of a non-invasive method, multiplex methylation specific PCR (MMSP), for early diagnosis of nasopharyngeal carcinoma. PLoS One, 7(11), Article e45908.

Zhou, Y., Nabeshima, K., Koga, K., Aoki, M., Hayashi, H., Hamasaki, M., \& Iwasaki, H. (2008). Comparison of Epstein-Barr virus genotypes and clinicohistopathological features of nasopharyngeal carcinoma between Guilin, China and Fukuoka, Japan. Oncology Reports, 19(6), 1413-1420. 